\title{
Identification of a Potential Third Component of the Male-Produced Pheromone of Anoplophora glabripennis and its Effect on Behavior
}

\author{
Damon J. Crook • David R. Lance • Victor C. Mastro
}

Received: 15 May 2014 / Revised: 25 September 2014 / Accepted: 4 November 2014 / Published online: 29 November 2014

(C) The Author(s) 2014. This article is published with open access at Springerlink.com

\begin{abstract}
The Asian longhorned beetle, Anoplophora glabripennis, is considered to be one of the most serious invasive pests of deciduous trees in North America. An efficient monitoring trap is needed to detect and delimit new introductions and assess population densities of established infestations. Previous studies on A. glabripennis have shown that males produce a two-component aggregation pheromone that consists of a 1:1 blend of 4-(n-heptyloxy)butan-1-ol and 4-(n-heptyloxy)butanal. Moderate attraction in field trapping studies suggested that there may be additional chemical cues missing. Volatiles from male $A$. glabripennis were examined to identify other potential pheromone components. Gas chromatographic / electroantennographic (GC/EAD) analyses of male aerations detected a consistent EAD-active response to a previously unidentified compound. This compound was identified as $(3 E, 6 E)-\alpha$-farnesene. Both male and female beetles were antennally responsive to this sesquiterpene, and both sexes were attracted to it in olfactometer bioassays at different doses. When $(3 E, 6 E)-\alpha$-farnesene was combined with 4- $(n-$ heptyloxy)butan-1-ol and 4-(n-heptyloxy)butanal, attraction of both sexes increased compared to assays using 4-(nheptyloxy)butan-1-ol and 4-( $n$-heptyloxy)butanal alone.
\end{abstract}

Keywords Pheromone $\cdot$ Invasive species $\cdot$ Cerambycidae $\cdot$ $(3 E, 6 E)$ - $\alpha$-farnesene

\section{Introduction}

The Asian longhorned beetle, Anoplophora glabripennis (Motschulsky) (Coleoptera: Cerambycidae: Lamiinae) is a

D. J. Crook $(\varangle) \cdot$ D. R. Lance $\cdot$ V. C. Mastro

Otis Laboratory, USDA APHIS PPQ CPHST, 1398 West Truck

Road, Buzzards Bay, MA 02542-1329, USA

e-mail: Damon.J.Crook@aphis.usda.gov serious wood-boring pest of hardwood trees that has been introduced from China to North America and Europe in wood packaging materials (Nehme et al. 2010). In North America, it was first detected in 1996 in Brooklyn, New York. Since then infestations from separate introductions have been found in Illinois (1998), New Jersey (2003), Toronto (2003), Massachusetts (2008), and Ohio (2011) (Wickham et al. 2012). Despite A. glabripennis having a host range of over 43 hardwood trees, North American populations favor six species of maple, Acer spp. (Haack et al. 1996, 2010; Hoover et al. 2014; Hu et al. 2009; Morewood et al. 2004). This preference for maple could have a drastic impact on lumber and maple syrup industries, as well as the urban forests of North America (Nehme et al. 2010). Up to 1.2 billion urban shade trees (worth up to $\$ 669$ billion) are at risk if A. glabripennis becomes well established in the U.S. (Nowak et al. 2001).

For current U.S. infestations, management is based on detection, tree removal, and insecticidal control (Wickham et al. 2012). Monitoring for A. glabripennis is both labor intensive and expensive, involving climbing trees and searching for oviposition scars, larval frass, sap flow, and emergence holes (Nehme et al. 2010). An attractant-baited trap that is capable of detecting low level populations could greatly improve the efficiency and cost-effectiveness of A. glabripennis surveys. Chemical attractants also could potentially be used in combination with biological control agents such as fungal pathogens specific to A. glabripennis (Dubois et al. 2004a, b; Hajek et al. 2006).

Several studies have shown that mate-finding in Anoplophora glabripennis involves numerous chemical cues and behaviors, although the exact sequence of events remains unclear (Hoover et al. 2014; Wickham, et al. 2012). Male A. glabripennis produce a blend of two dialkylethers, 4-(nheptyloxy)butan-1-ol and 4-(n-heptyloxy)butanal (Zhang et al. 2002). These compounds elicit GC-EAD responses in 
females, and are moderately attractive in laboratory assays, particularly when used with host odors such as (-)-linalool, trans-caryophyllene, and (Z)-3-hexen-1-ol (Meng et al. 2014; Nehme et al. 2009; Zhang et al. 2002). When these two maleproduced compounds were used in field bioassays in China (Ningxia Province), captures of $A$. glabripennis were significantly greater on baited traps than unbaited controls (Meng et al. 2014; Nehme et al. 2010). Wickham et al. (2012) stressed that current pheromone blends appear to be incomplete, and that identification of further pheromone components may lead to an 'operational-ready' lure for monitoring A. glabripennis effectively at low population densities. Here, we report the identification of $(3 E, 6 E)-\alpha$-farnesene, as a potential third pheromone component produced by males of A. glabripennis. We also demonstrate attraction of adult male and female beetles to $(3 E, 6 E)-\alpha$-farnesene in laboratory assays.

\section{Methods and Materials}

Insects All male adults used for aerations in 2012 and 2013 emerged from infested wood of red maple, Acer rubrum L., that were collected in and around Bethel, Ohio, and transported under permit to the USDA APHIS PPQ CPHST insect containment facility in Buzzards Bay, MA, USA.

2012 Aerations Insects were reared using similar protocols to those of Zhang et al. (2002). Adult virgin beetles were collected daily from infested logs before being kept individually in $2.1 \mathrm{~L}$ plastic jars (Rez-Tech Corporation, OH, USA). Three small holes in the lid of each jar provided ventilation. Insects were fed several approx $16 \mathrm{~cm}$ twigs of striped maple Acer pensylvanicum $L$. The twigs and a $4 \times 1 \mathrm{~cm}$ cotton dental wick extended through holes in the lid of a water-filled $120 \mathrm{ml}$ plastic cup (Dart Corporation, MI, USA) in the bottom of each jar. A coffee filter (8-12 cup size) was placed in the bottom of each jar to collect frass and absorb spilled water. Jars holding males and females were held in the same environmental chamber at $25{ }^{\circ} \mathrm{C}$, approx. $60 \%$ relative humidity $(\mathrm{RH})$ and 16:8 h L:D.

Lighting was provided by three standard fluorescent bulbs (4100 k 32 watt, 300 lx) in clear plastic light box fittings. Insects were fed for 10 days before being used in aerations. Male beetles were aerated in an environmental chamber that contained no females or plant material. Individual 10-day-old virgin adults were placed in $120 \mathrm{ml}$ glass canning jars (Bell/Uline, WI, USA) with Teflon screw-on lids that had two openings for tubing.

Battery operated pumps (Sensidyne, Clearwater, FL, USA) pulled air through each jar at a rate of $300 \mathrm{ml} / \mathrm{min}$. Ambient air was filtered through a 6-14 mesh activated charcoal (Fisher Scientific, Pittsburgh, PA, USA) inlet before entering the jar.
After leaving the jar, the air passed through two traps connected by a short section of Teflon tubing. Each trap was a $3 \mathrm{~mm}$ ID $\times 110 \mathrm{~mm}$ glass tube containing $200 \mathrm{mg}$ of $50 / 80 \mathrm{mesh}$ Super Q (Alltech, USA). All connections were sealed with Teflon ${ }^{\circledR}$ tape. Sampling was conducted at approximately $25^{\circ} \mathrm{C}$, approx $60 \% \mathrm{RH}$ and 16:8 h L:D using three standard fluorescent bulbs in clear plastic boxes (670 lx output). Three beetles, in separate jars, were aerated simultaneously. Once collected, aeration samples were eluted with $2 \mathrm{ml}$ of $\mathrm{CH}_{2} \mathrm{Cl}_{2}$ (J. T. Baker, NJ, USA). The three male extracts then were pooled before being concentrated to $100 \mu \mathrm{l}$ under a gentle stream of $\mathrm{N}_{2}$. All extracts were kept at $-20^{\circ} \mathrm{C}$ before GC/MS or GC/EAD analysis. Aerations lasted from $0900 \mathrm{~h}$ until $0900 \mathrm{~h}$ the next day ( $24 \mathrm{~h}$ ). During 2012, 13 groups of 10-dold virgin males ( 3 per group) were aerated. Nine virgin males between 15 and 23 days of age were also aerated and pooled into three samples ( 3 males each). Samples of headspace volatiles that contained the largest number of compounds (after examination by GC/MS) were used for GC/EAD recordings.

2013 Aerations Based on the results from 2012, we decided to change several aspects of the adult holding protocols the following year. The plastic jars were replaced by $1.9 \mathrm{~L}$ glass canning jars (Bell/Uline, WI,) with $7.5 \mathrm{~cm}$ diam wire mesh lids. Insects were fed for 10 days before being used in aerations. Males and females were kept in separate rooms within the containment facility on shelving units that were screened from ambient lab lighting. 'Laboratory' lighting in 2013 was changed to approximate more closely the wavelengths and intensity of 'natural' sunlight, as cerambycid beetles have been reported to behave sedentary or agitated under laboratory light conditions (Lacey et al. 2004). Specifically, the light systems each consisted of four T5 fluorescent lamps (Deep Blue Professional, City of Industry, CA, USA). Two were 39W Solarmax T5 10,000 K daylight lamps, and two were 39-W Solarmax T5 actinic 03 lamps that emitted a max blue phosphors peak at $420 \mathrm{~nm}$. The regimes for these two lamp types were controlled by automatic timers and set as follows: the blue actinic lamps turned on at $0630 \mathrm{~h}$ and shut off at $2100 \mathrm{~h}$; the two daylight bulbs turned on at $1030 \mathrm{~h}$ and switched off at $1530 \mathrm{~h}$. This lighting setup allowed for a morning and late evening actinic lamp period with a bright daylight period through midday. Light output from the actinic bulbs alone was measured at $80 \mathrm{~lx}$. Light output for the daylight and actinic lamps together was $450 \mathrm{~lx}$. The light system was suspended 15-20 $\mathrm{cm}$ above the rearing/feeding jars for both male and female colonies. In 2013, male 10-day-old virgin adults were aerated using the same jars and pump system as in 2012, but collections were done under the new lighting system described above at $25{ }^{\circ} \mathrm{C}$ and approx $55 \% \mathrm{RH}$. Adults were aerated without plant material being present. Collections were made between 1000 and $1500 \mathrm{~h}$ using a single Super Q 
cartridge of $200 \mathrm{mg}$ and eluted with $1.5 \mathrm{ml}$ of hexane (HPLC grade, OMNISOLV). Individual male collections were concentrated to $100 \mu \mathrm{l}$ under a gentle stream of $\mathrm{N}_{2}$, and stored at $-20{ }^{\circ} \mathrm{C}$ before $\mathrm{GC} / \mathrm{MS}$ or $\mathrm{GC} / \mathrm{EAD}$ analysis.

GC/MS Analyses Initial chemical analyses were conducted using a combined Agilent Technologies 6890 network gas chromatograph and 5973 mass-selective detector. The GC was equipped with a DB- 5 column $(30 \mathrm{~m} \times 0.25 \mathrm{~mm}$ I.D.; film thickness, $0.25 \mu \mathrm{m}$; J \& W Scientific Inc., Folsom, CA, USA). Helium was the carrier gas at a constant flow rate of $0.7 \mathrm{ml} /$ min. Injection was splitless at $275^{\circ} \mathrm{C}$. Oven temperature was held at $50{ }^{\circ} \mathrm{C}$ for $2 \mathrm{~min}$, programmed to $280{ }^{\circ} \mathrm{C}$ at $10^{\circ} \mathrm{C} / \mathrm{min}$ and held for $15 \mathrm{~min}$. Volatiles were identified based on their mass spectra (NIST version 2.0, 2002), Kovats indices (Kovats 1965; Van Den Dool and Kratz 1963) and comparison of the retention indices and mass spectra with those of available authentic synthetic compounds. Two separate authentic standards of $(3 E, 6 E)-\alpha$-farnesene were obtained from the University of California, Riverside, CA, USA, and USDAARS, Beltsville, MD, USA. The $(3 E, 6 E)-\alpha$-farnesene from Riverside, CA, was used for GC/EAD analysis and was at least $86 \%$ pure based on peak area values by GC. A sample of $(3 Z, 6 E)$ - $\alpha$-farnesene (containing $0.1 \%$ BHT) was obtained from the Natural Resources Canadian Forest Service laboratory (Fredericton, NB, Canada) and was at least $90 \%$ pure based on the peak area values by GC. A mixture of farnesene isomers was obtained from Sigma Aldrich Co. (St Louis, MO, USA). Synthesis methods for $(3 E, 6 E)-\alpha$-farnesene and (3Z,6E)- $\alpha$-farnesene are described by Khrimian et al. (2012) and Silk et al. (2010). The alcohol 4-(n-heptyloxy) butan-1-ol and aldehyde 4-(n-heptyloxy) butanal were obtained from Bedoukian Research Inc. (Danbury, CT, USA).

Electrophysiological Analysis (GC/EAD) The coupled GC/ EAD system used was as previously described by Crook et al. (2008) with a few modifications. Samples of aerations or standards $(2 \mu \mathrm{l})$ were injected in splitless mode onto a Hewlett Packard (Agilent) 6890 gas chromatograph with a DB-5MS-DG column $(30 \mathrm{~m} \times 0.25 \mathrm{~mm}$ ID, $0.25 \mu \mathrm{m}$ film thickness; J \& W Scientific Inc.) and a 1:1 effluent splitter that allowed simultaneous FID and EAD detection of the separated volatile compounds. Helium was the carrier gas $(2.5 \mathrm{ml} / \mathrm{min})$. Oven temperature was held at $50{ }^{\circ} \mathrm{C}$ for $2 \mathrm{~min}$, programmed to $280{ }^{\circ} \mathrm{C}$ at $10{ }^{\circ} \mathrm{C} / \mathrm{min}$ and held for $15 \mathrm{~min}$. Injector temperature was $275^{\circ} \mathrm{C}$. The $\mathrm{GC}$ outlets for the $\mathrm{EAD}$ and FID were $280^{\circ} \mathrm{C}$.

The column outlet for the EAD was held in a water-cooled humidified air stream $\left(20^{\circ} \mathrm{C}\right)$ flowing at $2 \mathrm{ml} / \mathrm{min}$ over the prepared antennae of adult $A$. glabripennis attached to an EAG probe (Syntech, Hilversum, the Netherlands). Antennae were prepared by cutting a single antenna at the base of the head of an adult beetle, and removing the lower pedicel and scape. A size 1 insect pin (BIOQUIP ${ }^{\circledR}$ ) was used to make three holes on the first flagellomere as well as the flagellomere third from the tip. Holes were made deep enough to make a clean opening in the cuticular surface to allow conducting gel (Spectra 360, Parker Laboratories, Fairfield, NJ, USA) to form an uninterrupted connection to the EAG probe. One of the electrodes on the probe was extended with gold wire (20 mm long) to accommodate the long length of the antennal preparation. This method preserved the tip of the antennae, eliminating the risk of removing vital sensillae specifically located there (Crook et al. 2003). The EAG probe was connected to an IDAC-232 serial data acquisition controller (Syntech). Signals were stored and analyzed on a PC equipped with the program EAD (version 2.6, Syntech).

Olfactometer Assays A Y-tube olfactometer (Analytical Research Systems Inc., Gainsville, FL, USA) was used to test biological activity of synthetic samples. All behavioral assays were done in a walk-in environmental chamber $\left(25^{\circ} \mathrm{C}\right.$, approx $60 \% \mathrm{RH})$ under a lighting system $(4 \times \mathrm{T} 5$ Solarmax fluorescent lamps) described earlier. The Y-tube was held at a $15^{\circ}$ angle upward from horizontal on a custom built holder placed $0.5 \mathrm{~m}$ below the lighting (measured at $300 \mathrm{~lx}$ ). The glass tube ( $3.5 \mathrm{~cm}$ internal diam) had a $15 \mathrm{~cm}$ main stem that branched into two $13 \mathrm{~cm}$ arms angled at $90^{\circ}$. Each arm then was connected to a separate glass tube that contained the stimulus or a solvent/blank control. Charcoal filtered air was bubbled through distilled water and then into each of the two arms at $1.0 \mathrm{l} / \mathrm{min}$ using a 2-channel air delivery system (Analytical Research Systems Inc., Gainesville, FL, USA).

Male and female adults between 15 and 40-day-old were used for all olfactometer bioassays. Individual beetles used in these bioassays were from 2013 colonies (see above). Insects were feeding on twigs until used in tests, i.e., with no starvation period. A total of 25 replicates was completed for each treatment, using one beetle per replicate.

Stock solutions of ( $3 E, 6 E)-\alpha$-farnesene (CA sample), 4-( $n$ heptyloxy)butan-1-ol and 4-(n-heptyloxy)butanal (10 $\mu \mathrm{g}$ per $10 \mu \mathrm{l}$ hexane) were used for all tests.

Bioassays were conducted to test attraction to $(3 E, 6 E)-\alpha$ farnesene either alone $(1 \mu \mathrm{g}, 10 \mu \mathrm{g}$, and $20 \mu \mathrm{g}$ levels $)$ or in combination (1:1:1) with 4-( $n$-heptyloxy)butan-1-ol and 4-(nheptyloxy)butanal (at the $1 \mu \mathrm{g}$ and $10 \mu \mathrm{g}$ concentrations). These doses were selected based on previous olfactometer bioassays involving A. glabripennis (Nehme et al. 2009; Zhang et al. 2002). Treatments were offered against a hexane control. A 1:1 component mix of 4-(n-heptyloxy)butan-1-ol and 4-(n-heptyloxy)butanal also was tested at the $10 \mu \mathrm{g}$ concentration against a hexane control. The test stimulus was dispensed onto a strip of filter paper $(10 \times 40 \mathrm{~mm})$, and placed in the tube connected to one arm of the olfactometer. An identical filter paper strip with the same amount of hexane was placed in the other arm of the olfactometer. The Y-tube 
was rinsed with acetone between each individual test. Treatment and control arms were alternated every other replicate to control for possible positional effects. For each test, a single male or female beetle was placed at the end of the main stem and given $5 \mathrm{~min}$ to choose between the two stimuli. A choice was recorded when the beetle passed a line, $8 \mathrm{~cm}$ beyond the branch point of each arm. No choice was recorded if the beetle failed to pass either line after the 5 min period. Insects that did not make a choice were excluded from statistical analysis. Out of 388 olfactometer tests only 13 beetles failed to make a choice $(3.35 \%)$. All experiments were conducted between 1100 and $1500 \mathrm{~h}$, when beetles appeared to be most active.

Statistical Analyses To test whether the test stimulus attracted more beetles than solvent control in Y-tube olfactometer bioassays, a $X^{2}$ analysis goodness-of-fit test was used. Values of $X^{2}>3.84$ with $1 d$. $f$. were significant at $\alpha=0.05$ (Epistat 2.1, TX, 1983).

\section{Results}

Identification of Male-Specific Chemicals Aerations completed during 2012 contained the two male-produced compounds, 4-(n-heptyloxy)butanal and 4-(n-heptyloxy)butan-1-ol, previously reported by Zhang et al. (2002). Of these two compounds, 4-( $n$-heptyloxy)butanal did not elicit a consistent antennal response during GC/EAD tests. Occasional antennal responses were observed to the 4-( $n$-heptyloxy)butan-1-ol from male aeration samples passed over female antennae. A consistent GC/EAD response from females was found for a trace peak (retention time $15.1 \mathrm{~min}$ ), from several pooled samples of aerations collected from males during 2012 (Fig. 1). The peak at 15.1 min was absent from aeration samples of females (fed and unfed) or striped maple twigs used in rearing. This compound elicited responses from the antennae of virgin female $A$. glabripennis that had been fed twigs for 1, 2, and 3 days (Fig. 2), and from the antennae of 14-day-old fed virgin females (data not shown).

In 2013, using the Solarmax T5 lighting system, we observed an increase in the abundance of the unidentified compound in several samples of headspace volatiles collected from male beetles (Fig. 3). The EI-mass spectrum (Fig. 4) of the unknown compound closely matched that of an isomer of $\alpha$-farnesene (NIST version 2.0, 2002), in particular, the $(3 E, 6 E)$ - $\alpha$-farnesene

To identify the antennally active isomer of $\alpha$-farnesene, we compared synthetic $(3 Z, 6 E)-\alpha$-farnesene and $(3 E, 6 E)-\alpha$ farnesene via GC/MS (Figs. 3 and 4). The $(3 E, 6 E)-\alpha-$ farnesene had an identical retention time (15.13) to that of the unknown compound in the male aeration (Fig. 3). Both the synthetic $(3 E, 6 E)-\alpha$-farnesene and the unknown compound in the male aeration had identical Kovats indices of 1511 on a DB-5 column. Adams (1995) reported a Kovats index of 1508 for this compound on a DB-5 column.

Multiple GC/EAD responses were consistently observed to components of the commercial mixture of farnesene isomers (RT 13-18 min) from both female and male beetles (Fig. 5).

Both male and female $A$. glabripennis antennae gave consistent GC/EAD responses to a synthetic mix of 4-(nheptyloxy)butanal, 4-(n-heptyloxy)butan-1-ol, and $(3 E, 6 E)-\alpha$-farnesene (Fig. 6).

Olfactometer Assays Both male and female A. glabripennis exhibited significant positive taxis toward $(3 E, 6 E)-\alpha-$ farnesene when it was tested alone against a hexane control $(N=25)$ (Table 1). Females showed non-significant 56 and $52 \%$ positive responses to 1 and $10 \mu \mathrm{g}$ doses of $(3 E, 6 E)-\alpha$ farnesene, but a significant $76 \%$ positive response when a $20 \mu \mathrm{g}$ dose was tested. Males exhibited significant positive
Fig. 1 GC/EAD response of 2 day-old female Anoplophora glabripennis to a male aeration sampled in $2012((1) 4-(n-$ heptyloxy)butanal; (2) 4-(nheptyloxy)butan-1-ol; (3) unknown)

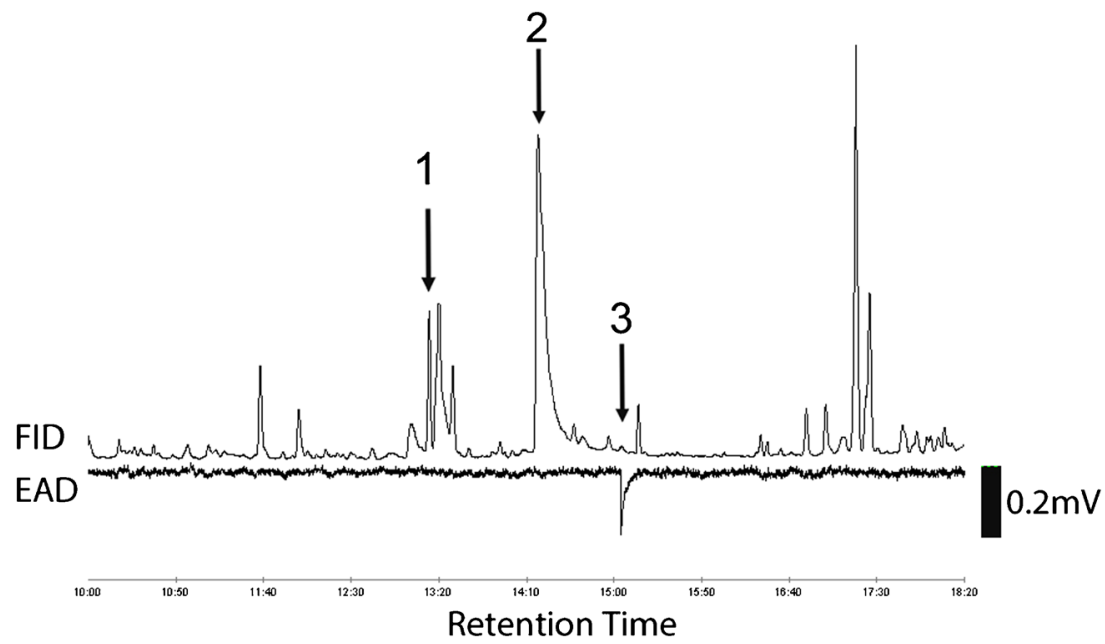



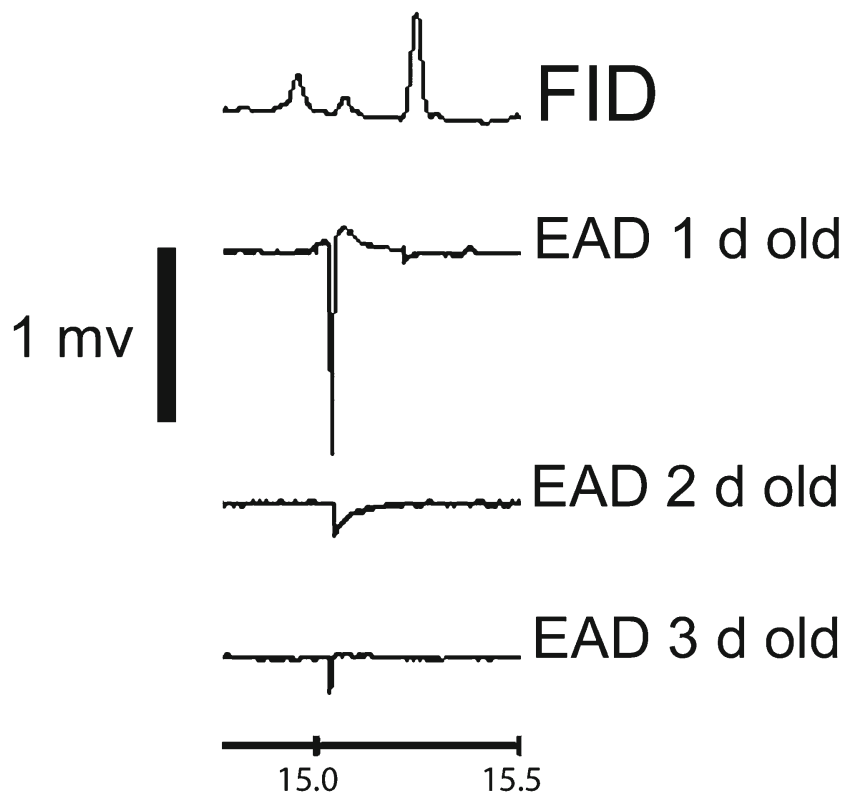

\section{Retention time}

Fig. 2 EAD responses of 1, 2, and 3-day-old fed virgin female Anoplophora glabripennis to unknown peak in male aeration sample from 2012

taxis at 1 and $10 \mu \mathrm{g}$ doses of $(3 E, 6 E)$ - $\alpha$-farnesene (76 and $72 \%$, respectively) but a non-significant $32 \%$ response to

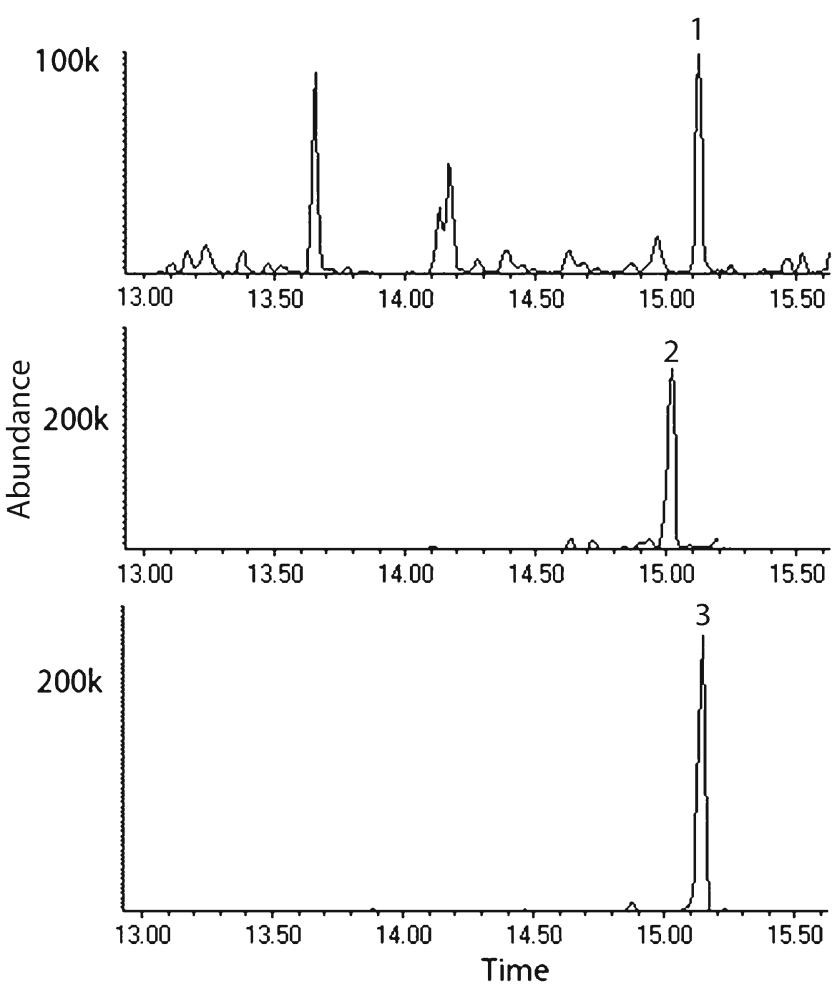

Fig. 3 Total ion chromatogram of (1) unidentified peak in GC/MS analysis of aeration sample from male Anoplophora glabripennis collected under Solarmax T5 lighting system in 2013; (2) synthetic standard of $(3 Z, 6 E)-\alpha$-farnesene; (3) synthetic standard of $(3 E, 6 E)$ - $\alpha$-farnesene
$(3 Z, 6 E)-\alpha$-farnesene
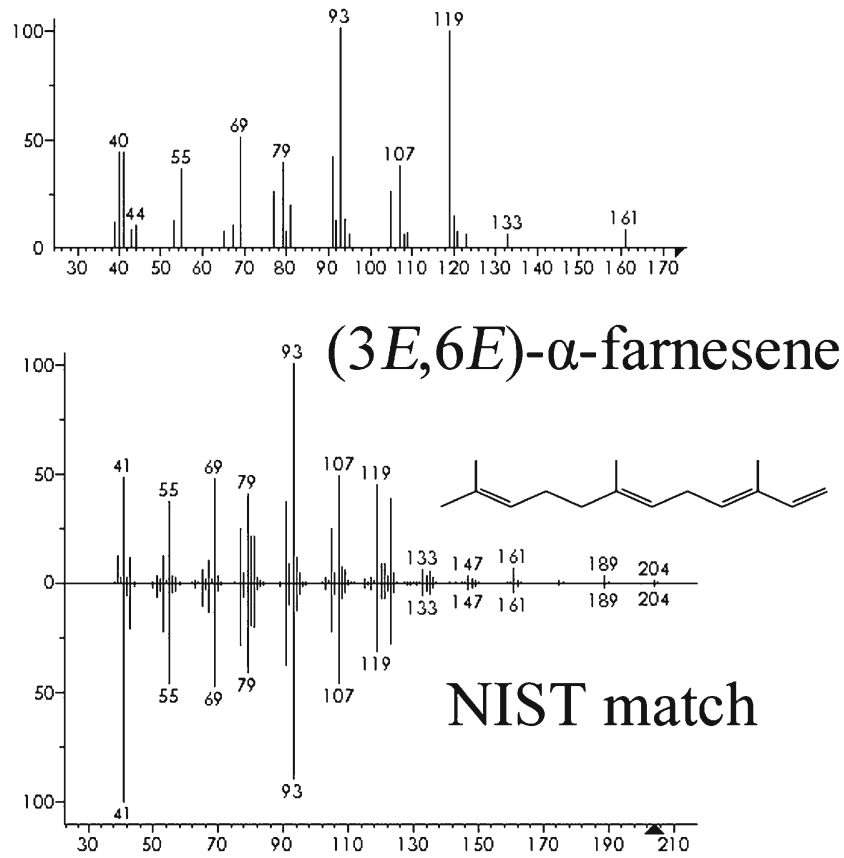

Fig. 4 EI mass spectra of a synthetic standard of $(3 Z, 6 E)-\alpha$-farnesene (upper), synthetic standard of (3E,6E)- $\alpha$-farnesene (middle), and NIST library match for $(3 E, 6 E)$ - $\alpha$-farnesene (lower)

$20 \mu \mathrm{g}$. Males did not show a significant attraction (48 \%) to a $10 \mu \mathrm{g}$ dose of mixed farnesene isomers.

Female responses to the two known male-produced pheromone components were increased by addition of $(3 E, 6 E)-\alpha-$ farnesene (Table 2). When a 1:1 blend of 4-( $n$ heptyloxy)butan-1-ol and 4-( $n$-heptyloxy)butanal (1 ug each) was presented to females against a hexane control, a $44 \%$ non-significant response to the stimulus was observed. When $1 \mu \mathrm{g}$ of $(3 E, 6 E)$ - $\alpha$-farnesene was added to the $1: 1$ pheromone blend, female response increased to a significant $72 \%$ positive response over the hexane control. When the dose of 4-(nheptyloxy)butan-1-ol and 4-( $n$-heptyloxy)butanal (1:1 mix) was increased to $10 \mu \mathrm{g}$ and presented to females (against a hexane control), a $48 \%$ response to the stimuli was observed. The response of female beetles to the two-component pheromone blend was seemingly improved upon the addition of $10 \mu \mathrm{g}$ of $(3 E, 6 E)-\alpha$-farnesene $(64 \%)$ although the response was not significant.

Male responses to the two known male-produced pheromone components improved upon the addition of $(3 E, 6 E)-\alpha-$ farnesene (Table 3$)$. When a $1: 1$ blend of $4-(n-$ heptyloxy)butan-1-ol and 4-(n-heptyloxy)butanal (1ug each) was presented to males against a hexane control a $52 \%$ nonsignificant response to the stimulus was observed. When a $1 \mu \mathrm{g}$ amount of $(3 E, 6 E)-\alpha$-farnesene was added to the $1: 1$ pheromone blend, male response increased to a significant $76 \%$ positive response over the hexane control. When 
Fig. 5 Typical GC/EAD responses of adult male and female Anoplophora glabripennis to a commercially-available mixture injection that consisted of 2000 ng Sigma Aldrich

farnesene isomers in $1 \mathrm{ul} \mathrm{hexane}$

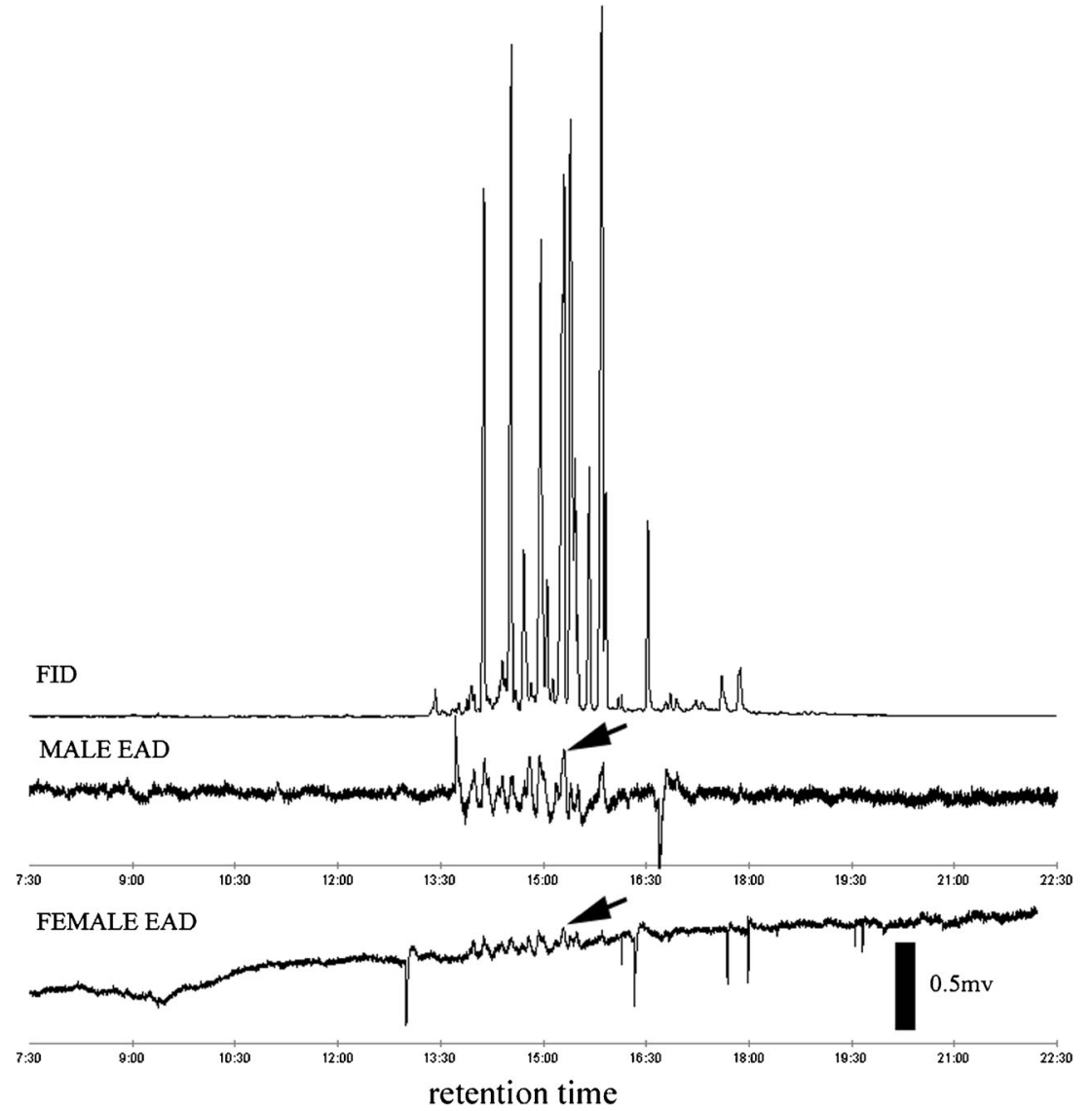

presented with a higher dosage of $10 \mu \mathrm{g}$ per component, males did not show a significant response to either the $1: 1$ blend of pheromone components or the $1: 1: 1$ mixture with $(3 E, 6 E)-\alpha-$ farnesene (Table 3).

\section{Discussion}

The results provide evidence that $(3 E, 6 E)-\alpha$-farnesene is a potential third component of the male-produced aggregation pheromone that may play a role in the mating behavior and complex chemical ecology of $A$. glabripennis. We have never observed $(3 E, 6 E)$ - $\alpha$-farnesene in aerations from either fed or unfed female $A$. glabripennis or from twig cuttings of striped maple (data not shown), and the compound is thus assumed to be male-specific. The compound was attractive to both male and female beetles in an olfactometer bioassay and could enhance the attractiveness of the two pheromone components identified previously, 4-(n-heptyloxy)butan-1-ol and 4-(nheptyloxy)butanal. More testing is planned to confirm field activity, and to determine optimum release rates of these three male-produced compounds.

Within the Cerambycidae, the majority of pheromones identified to date are produced by males and attract both sexes (Hanks and Millar 2013). This is particularly true in the subfamily Lamiinae, of which $A$. glabripennis is a member (Allison et al. 2012; Fierke et al. 2012; Fonseca et al. 2010; Mitchell et al. 2011; Pajares et al. 2010; Teale et al. 2011). In the last decade, research has revealed that there is substantial pheromonal parsimony within the Cerambycidae (Hanks and Millar 2013). In the Lamiinae, male Monochamus galloprovincialis (Olivier) (Pajares et al. 2010), M. alternatus (Hope) (Teale et al. 2011) and M. sutor L. (Pajares et al. 2013) all produce 2undecyloxy-1-ethanol as an aggregation pheromone. The structure of this is similar to the dialkyl ethers $4-(n-$ heptyloxy)butan-1-ol and 4-(n-heptyloxy)butanal produced by $A$. glabripennis (Zhang et al. 2002) and to 2-(4-heptyloxy-1-butyloxy)-1-ethanol, produced by male M. leuconotus (Pascoe) (Hall et al. 2006).

The use of terpenoids as a male produced aggregation pheromone has been reported by Lacey et al. (2008) for the cerambycine species Megacyllene caryae (Gahan). A blend of alkanoids, terpenoids, and aromatic alcohols was found to be a general aggregation pheromone for this species in olfactometer studies. Mitchell (2012) reported that male Megacyllene robiniae (Forster) produced six terpenoids (not produced by females), which may be minor pheromone components. One of the compounds identified by Mitchell (2012) was $\beta$-farnesene. 
$\alpha$-Farnesene was first reported as a bioactive volatile re-
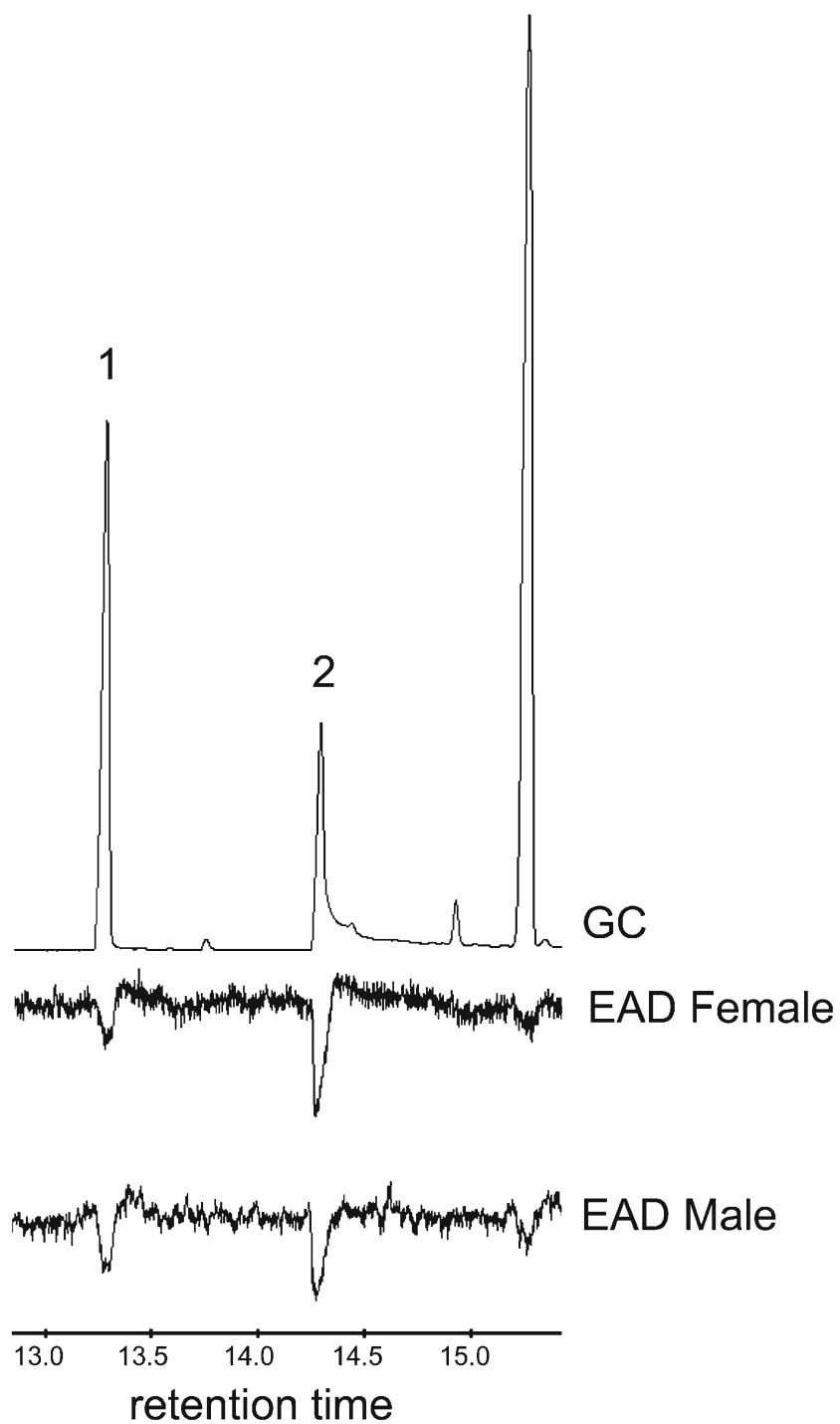

Fig. $6 \mathrm{GC} / \mathrm{EAD}$ responses of adult female (18-day-old) and male (21day-old) Anoplophora glabripennis to a synthetic mix of $200 \mathrm{ng}$ each of (1) 4-(n-heptyloxy)butanal, (2) 4-(n-heptyloxy)butan-1-ol./ and (3) $(3 E, 6 E)-\alpha$-farnesene leased from the wax of apple skin (Huelin and Murray 1966: Murray and Huelin 1964). Both the $(3 E, 6 E)$ and $(3 Z, 6 E)$ isomers of $\alpha$-farnesene have been found to increase calling and oviposition rates in codling moth, Cydia pomonella (L.) females (Yan et al. 2003). Electrophysiological responses of antennae to $(3 E, 6 E)$ - $\alpha$-farnesene and $(3 Z, 6 E)$ - $\alpha$-farnesene have been reported for a number of insect species (Cha et al. 2008; Rodriguez-Saona et al. 2006; Tasin et al. 2005; Wie and Kang 2006; Yarden et al. 1996). Isomers of $\alpha$-farnesene have been linked to behavioral responses such as taxis (Cha et al. 2008; Landolt et al. 2000; Silk et al. 2010; Wie and Kang 2006), oviposition (Sutherland et al. 1977), and alarm calling (Šobotnik et al. 2008).

Silk et al. (2010) found that farnesene isomers may play a role in the chemical ecology of the cerambycid, Tetropium fuscum. There is strong evidence to show that stress-induced sesquiterpene components of conifers, including farnesene, may play a role in enabling Tetropium fuscum to locate a weakened host (Silk et al. 2010). Silk et al. (2010) found that T. fuscum gave a consistent $\mathrm{GC} / \mathrm{EAD}$ response to synthetic $(3 Z, 6 E)-\alpha$-farnesene, which matched the GC retention time of the antennally active unknown sesquiterpene in spruce oil. An antennal response to $(3 E, 6 E)$ - $\alpha$-farnesene also was observed in a small number of replicates but was lower in amplitude (Silk et al. 2010). Our electrophysiological recordings for male and female A. glabripennis showed that they also gave multiple antennal responses to isomers of farnesene in a mixture of isomers, although they were not observed in male aerations. These other antennally-active farnesene isomers could be repellant to adult beetles, and may prevent this readily-available mixture of isomers being a viable lure option. In our preliminary olfactometer test, $10 \mu \mathrm{g}$ of the mixture of farnesene isomers were not attractive to males. The basic 'structural skeleton' of farnesene may elicit an antennal response in $A$. glabripennis, but the specific $(3 E, 6 E)-\alpha-$ farnesene appears to be necessary for a behavioral response. The $(3 E, 6 E)-\alpha$-farnesene isomer appears to be a pheromone

Table 1 Two-choice olfactometer behavioral assays comparing responses of male and female Anoplophora glabripennis $(N=25)$ to different doses of $(3 E, 6 E)-\alpha$-farnesene $v s$. a hexane control ( $X^{2}$ analysis $)$

\begin{tabular}{|c|c|c|c|c|c|c|c|}
\hline $\begin{array}{l}\text { Sex of beetle } \\
\text { tested }\end{array}$ & $\begin{array}{l}\text { Odor source } 1 \\
((3 E, 6 E) \text { - } \\
\alpha \text {-farnesene })\end{array}$ & $\begin{array}{l}\text { Odor source } 2 \\
\text { (hexane) }\end{array}$ & Choice 1 & Choice 2 & $\begin{array}{l}\% \text { response } \\
\text { to choice } 1\end{array}$ & $X^{2}$ & $P$ \\
\hline Female & $1 \mu \mathrm{g}$ & $1 \mu \mathrm{l}$ & 14 & 11 & $56 \%$ & 0.16 & 0.921 \\
\hline Female & $10 \mu \mathrm{g}$ & $10 \mu l$ & 13 & 12 & $52 \%$ & 0.00 & NS \\
\hline Female & $20 \mu \mathrm{g}$ & $20 \mu l$ & 19 & 6 & $76 \%$ & 5.76 & 0.0093 \\
\hline Male & $1 \mu \mathrm{g}$ & $1 \mu l$ & 19 & 6 & $76 \%$ & 5.76 & 0.0093 \\
\hline Male & $10 \mu \mathrm{g}$ & $10 \mu l$ & 18 & 7 & $72 \%$ & 4.00 & 0.0269 \\
\hline Male & $20 \mu \mathrm{g}$ & $20 \mu l$ & 8 & 17 & $32 \%$ & 2.56 & 0.0693 \\
\hline Male & $10 \mu \mathrm{g}$ mixture of isomers & $10 \mu l$ & 12 & 13 & $48 \%$ & 0.00 & NS \\
\hline
\end{tabular}


Table 2 Two-choice olfactometer behavioral assays comparing responses of female Anoplophora glabripennis $(N=25)$ to blends of 4-( $n$ heptyloxy)butan-1-ol and 4-( $n$-heptyloxy)butanal with and without $(3 E, 6 E)-\alpha$-farnesene $\left(\chi^{2}\right.$ analysis)

\begin{tabular}{|c|c|c|c|c|c|c|c|}
\hline Sex of beetle tested & $\begin{array}{l}\text { Odor source } 1: 4-(n \text {-heptyloxy)butan-1-ol } \\
+4-(n \text {-heptyloxy)butanal }+ \\
(3 E, 6 E) \text { - } \alpha \text {-farnesene }(\mu \mathrm{g})\end{array}$ & $\begin{array}{l}\text { Odor source 2: } \\
\text { hexane }(\mu l)\end{array}$ & Choice 1 & Choice 2 & $\begin{array}{l}\% \text { response to } \\
\text { choice } 1\end{array}$ & $\chi^{2}$ & $P$ \\
\hline Female & $1 \mu \mathrm{g}+1 \mu \mathrm{g}+0 \mu \mathrm{g}$ & $2 \mu 1$ & 11 & 14 & $44 \%$ & 0.16 & 0.921 \\
\hline Female & $1 \mu \mathrm{g}+1 \mu \mathrm{g}+1 \mu \mathrm{g}$ & $3 \mu \mathrm{l}$ & 18 & 7 & $72 \%$ & 4 & 0.027 \\
\hline Female & $10 \mu \mathrm{g}+10 \mu \mathrm{g}+0 \mu \mathrm{g}$ & $20 \mu \mathrm{l}$ & 12 & 13 & $48 \%$ & 0 & NS \\
\hline Female & $10 \mu \mathrm{g}+10 \mu \mathrm{g}+10 \mu \mathrm{g}$ & $30 \mu \mathrm{l}$ & 16 & 9 & $64 \%$ & 1.44 & 0.162 \\
\hline
\end{tabular}

component for the Mediterranean fruit fly Ceratitis capitata (Wied.) (Heath et al. 1991), and recently has been identified as being a male-produced pheromone component of the bananaspotting bug, Amblypelta lutescens lutescens Distant (Heteroptera: Coreidae) by Khrimian et al. (2012).

Our identification of an $\alpha$-farnesene isomer as a potential attractant for A. glabripennis supports findings of previous studies done on another Anoplophora species. Volatiles that have been implicated in short- and long-distance mate location in the citrus longhorned beetle, Anoplophora malasiaca (referred to subsequently as $A$. chinensis; see Lingafelter and Hoebeke 2002) include the sesquiterpenes $\beta$-elemene, $\beta$ caryophyllene, $\alpha$-humulene, $(3 E, 6 E)-\alpha$-farnesene, and several unidentified compounds (Yasui et al. 2007, 2008). The laboratory and field assays done by Yasui et al. (2007) show that both male and female $A$. chinensis use sesquiterpenes such as $(3 E, 6 E)$ - $\alpha$-farnesene for mate location over both short and long distances. Adachi (1990) differentiated smalland large-scale movements for $A$. chinensis. The former consisted of walking bouts interspersed with brief flights between trees. The latter comprised walking on the ground and flying longer distances. After using sesquiterpenes in field tests, Yasui et al. (2007) concluded that sesquiterpenes were more important for attraction over a longer distance. After landing in the vicinity of the odor source, adults located mates using shorter range olfactory cues. The final approach then was made by visual and olfactory cues (Fukaya et al. 2005a, b) before direct antennal contact/reception of the femaleproduced contact pheromone (Fukaya et al. 1999).
A similar scenario for mate location in A. glabripennis also has been suggested in which $A$. glabripennis utilizes maleand female-produced long range pheromones to find a mate among a forest of host odors (Hoover et al. 2014; Nehme et al. 2010; Wickham et al. 2012). Li et al. (1999) suggested that a female-produced contact pheromone played a role in the final stages of mate recognition. Zhang et al. (2003) compared male and female body washes of adults and identified five monounsaturated hydrocarbons that elicited copulatory behavior immediately after antennal contact. Female A. glabripennis also have been found to utilize a four component, sex specific trail pheromone (Hoover et al. 2014). These components were identified as 2-methyldocosane and (Z)-9-tricosane (major components) as well as (Z)-9-pentacosene and (Z)-7pentacosene (minor components).

Identification of 'long range' attractants is essential for an effective field lure, and both female- and male-produced compounds have been examined as candidate long-range attractants for A. glabripennis. Wickham et al. (2012) tested the hypothesis that one or more female-produced contact sex pheromones were precursors that underwent abiotic oxidation to yield more volatile, longer-range pheromone components. Males were found to be preferentially attracted to ozonized female body washes over crude body washes. In GC/EAD analyses, three antennallyactive aldehydes, heptanal, nonanal, and hexadecanal were detected. In field tests on traps in China, combinations of these aldehydes with linalool oxide and other host kairomones captured more beetles than controls, and captured significantly more males. Wickham et al. (2012) proposed that females select

Table 3 Two-choice olfactometer behavioral assays comparing responses of male Anoplophora glabripennis $(N=25)$ to blends of $4-(n$ heptyloxy)butan-1-ol and 4-( $n$-heptyloxy)butanal with and without $(3 E, 6 E)-\alpha$-farnesene ( $\chi^{2}$ analysis)

\begin{tabular}{|c|c|c|c|c|c|c|c|}
\hline Sex of beetle tested & $\begin{array}{l}\text { Odor source } 1 \text { : } 4 \text { - }(n \text {-heptyloxy)butan-1-ol } \\
+4 \text { - }(n \text {-heptyloxy)butanal }+(3 E, 6 E)- \\
\alpha \text {-farnesene }(\mu \mathrm{g})\end{array}$ & $\begin{array}{l}\text { Odor source 2: } \\
\text { hexane }(\mu l)\end{array}$ & Choice 1 & Choice 2 & $\begin{array}{l}\% \text { response } \\
\text { to choice } 1\end{array}$ & $\chi^{2}$ & $P$ \\
\hline Male & $1 \mu g+1 \mu g+0 \mu g$ & $2 \mu \mathrm{l}$ & 13 & 12 & $52 \%$ & 0 & NS \\
\hline Male & $1 \mu \mathrm{g}+1 \mu \mathrm{g}+1 \mu \mathrm{g}$ & $3 \mu 1$ & 19 & 6 & $76 \%$ & 5.76 & 0.0093 \\
\hline Male & $1 \mu \mathrm{g}+1 \mu \mathrm{g}+0 \mu \mathrm{g}$ & $20 \mu \mathrm{l}$ & 12 & 13 & $48 \%$ & 0 & NS \\
\hline Male & $1 \mu \mathrm{g}+1 \mu \mathrm{g}+1 \mu \mathrm{g}$ & $30 \mu \mathrm{l}$ & 8 & 17 & $32 \%$ & 2.56 & 0.0693 \\
\hline
\end{tabular}


host trees and after a period of feeding, release volatiles that attract males. They hypothesized that the two known maleproduced pheromones acted over a shorter range once males had been attracted to the host tree. If this behavioral scenario is correct, then our newly identified component potentially could increase this short range attraction of females.

Our results show that by itself, $(3 E, 6 E)-\alpha$-farnesene is attractive to both male and female A. glabripennis at varying doses. Males appear to show significant responses in assays to lower doses, which may indicate that $(3 E, 6 E)$ - $\alpha$-farnesene is being used as a general aggregation pheromone but is repellent and dispersive to males at higher concentrations. Females appeared to be more responsive to $(3 E, 6 E)$ - $\alpha$-farnesene at higher doses. The other two previously identified male pheromones, 4-(n-heptyloxy)butan-1-ol and 4-(n-heptyloxy)butanal were not attractive individually at $1 \mu \mathrm{g}$ doses to male or female A. glabripennis in olfactometer tests (Nehme et al. 2009). Virgin females, but not virgin males, showed a significant olfactometer response to a $1 \mu \mathrm{g}: 1 \mu \mathrm{g}$ combination of the two components (Nehme et al. 2009). Female responses to these two components appeared to be enhanced by host plant kairomones, and field tests have shown statistically significant but limited attraction (Meng et al. 2014; Nehme et al. 2010). This suggested that other chemical cues or signals may be involved in improving the likelihood of finding a mate (Hoover et al. 2014). We did not see significant attraction of male or female A. glabripennis to a 1:1 mix of 4-(n-heptyloxy) butan-1-ol and 4-( $n$-heptyloxy) butanal at either the $1 \mu \mathrm{g}: 1 \mu \mathrm{g}$ or $10 \mu \mathrm{g}: 10 \mu \mathrm{g}$ dosages in any of our olfactometer tests. Significant attraction was observed only upon the addition of the $(3 E, 6 E)-\alpha$-farnesene $(1: 1: 1)$ for females at the $10 \mu \mathrm{g}$ dose. Further research is needed to determine if $(3 E, 6 E)-\alpha$-farnesene is a third component of a male produced pheromone blend, or if it is a general aggregation pheromone that is effective by itself.

Acknowledgments We thank Tracy Ayer, Carrie Crook, and Natalie Leva for technical assistance and support (USDA, APHIS PPQ CPHST, Otis, MA) as well as Dr. Ann Ray (Xavier University) for comments on an earlier draft of the manuscript. We also thank Prof. Jocelyn Millar (University of California), Dr. Peter Silk (Natural Resources CanadaCanadian Forest Service), and Dr. Ashot Khrimian (USDA-ARS, Beltsville) for their donations of specific farnesene isomers. This research was funded by the USDA APHIS PPQ.

Open Access This article is distributed under the terms of the Creative Commons Attribution License which permits any use, distribution, and reproduction in any medium, provided the original author(s) and the source are credited.

\section{References}

Adachi T (1990) Population studies of Anoplophora malasiaca adults (Coleoptera: Cerambycidae) in a citrus grove. Res Popul Ecol 32: $15-32$
Adams RP (1995) Identification of essential oil components by gas chromatography/mass spectrometry. Allured Publishing Corporation, Carol Stream

Allison JD, McKenna JL, Millar JG, McElfresh JS, Mitchell RF, Hanks LH (2012) Response of woodborers Monochamus carolinensis and Monochamus titillator to known cerambycid pheromones in the presence and absence of the host plant volatile. Environ Entomol 41:1587-1596

Cha D, Nojima S, Hesler SP, Zhang A, Linn CE, Roelofs WL, Loeb GM (2008) Identification and field evaluation of grape shoot volatiles attractive to female grape berry moth (Paralobesia viteana). $\mathrm{J}$ Chem Ecol 34:1180-1189

Crook DJ, Higgins RA, Ramaswamy SB (2003) Antennal morphology of the soybean stemborer Dectes texanus texanus LeConte (Coleoptera: Cerambycidae). J Kansas Entomol Soc 76:397-405

Crook DJ, Khrimian A, Francese JA, Fraser I, Poland TM, Sawyer AJ, Mastro VC (2008) Development of a host-based semiochemical lure for trapping emerald ash borer Agrilus planipennis (Coleoptera: Buprestidae). Environ Entomol 37:356-365

Dubois T, Li Z, Jiafu H, Li Z (2004a) Evaluating the efficiency of entomopathogenic fungi against the Asian longhorned beetle, Anoplophora glabripennis (Coleoptera: Cerambycidae), by using cages in the field. Environ Entomol 33:62-74

Dubois T, Li Z, Jiafu H, Hajek AE (2004b) Efficacy of fiber bands impregnated with Beauveria brongniartii cultures against the Asian longhorned beetle, Anoplophora glabripennis (Coleoptera: Cerambycidae). Biol Control 31:320-328

Fierke MK, Skabeikis DD, Millar JG, Teale SA, McElfresh JS, Hanks LM (2012) Identification of a male-produced pheromone for Monochamus scutellatus scutellatus and an attractant for the congener Monochamus notatus (Coleoptera: Cerambycidae). J Econ Entomol 105:2029-2034

Fonseca MG, Vidal DM, Zarbin PHG (2010) Male-produced sex pheromone of the cerambycid beetle Hedypathes betulinus: chemical identification and biological activity. J Chem Ecol 36:1132-1139

Fukaya M, Akino T, Yasuda T, Yasui Y, Wakamura S (1999) Visual and olfactory cues for mate orientation behavior in male white-spotted longicorn beetle, Anoplophora malasiaca (Thomson) (Coleoptera: Cerambycidae). Entomol Exp Appl 111:111-115

Fukaya M, Akino T, Yasui H, Yasuda S, Wakamura S, Yamamura K (2005a) Effect of size and color of female models for male mate orientation in the white-spotted longicorn beetle, Anoplophora malasiaca (Coleoptera: Cerambycidae). Appl Entomol Zool 40: 513-519

Fukaya M, Yasui H, Yasuda S, Akino T, Wakamura S (2005b) Female orientation to the male in the white-spotted longicorn beetle, Anoplophora malasiaca by visual and olfactory cues. Appl Entomol Zool 40:63-68

Haack R, Cavey JF, Hoebeke ER, Law KL (1996) Anoplophora glabripennis: a new tree-infesting exotic cerambycid invades New York. Newslett Mich Entomol Soc 41:1-3

Haack R, Herard F, Sun J, Turgeon J (2010) Managing invasive populations of Asian longhorned beetle and citrus longhorned beetle: a worldwide perspective. Annu Rev Entomol 55:521-546

Hajek AE, Huang B, Dubois T, Smith MT, Li Z (2006) Field studies of control of Anoplophora glabripennis (Coleoptera: Cerambycidae) using fiber bands containing the entomopathogenic fungi Metarhizium anisopliae and Beauveria brongniartii. Biocontrol Sci Tech 16:329-343

Hall DR, Kutywayo D, Chanika C, Nyirenda S, Oduor G (2006) Chemistry of the African coffee stemborer, Monochamus leuconotus: but where's the ecology? Abstracts, 22nd Meeting of the International Society of Chemical Ecology. Barcelona, Spain, p 306

Hanks LM, Millar JG (2013) Field bioassays of cerambycid pheromones reveal widespread parsimony of pheromone structures, synergism 
by host plant volatiles, and antagonism by components from heterospecifics. Chemoecology 23:21-44

Heath RR, Landolt PJ, Tumlinson JH, Chambers DL, Murphy RE, Doolittle RE, Dueben BD, Sivinski J, Calkins CO (1991) Analysis, synthesis, formulation, and field testing of three major components of male Mediterranean fruit fly pheromone. J Chem Ecol 17:1925-1940

Hoover K, Keena M, Nehme M, Wang S, Meng P, Zhang A (2014) Sexspecific trail pheromone mediates complex mate finding behavior in Anoplophora glabripennis. J Chem Ecol 40:169-180

Hu JF, Angeli S, Schuetz S, Luo YQ, Hajek AE (2009) Ecology and management of exotic and endemic Asian longhorned beetle Anoplophora glabripennis. Agric For Entomol 11:359-375

Huelin FE, Murray KE (1966) $\alpha$-Farnesene in the natural coating of apples. Nature 210:1260-1261

Khrimian A, Fay HAC, Guzman F, Chauhan K, Moore C, Aldrich JR (2012) Pheromone of the banana-spotting bug, Amblypelta lutescens lutescens Distant (Heteroptera: Corenda): identification, synthesis and field bioassay. Psyche J Entomol. doi:10.1155/2012/536149

Kovats ES (1965) Gas Chromatographic characterization of organic substances in the retention index system. In: Giddings JC, Keller RA (eds) Advances in chromatography. Marcel Dekker, Inc., New York, pp 229-247

Lacey ES, Ginzel MD, Millar JG, Hanks LM (2004) Male-produced aggregation pheromone of the cerambycid beetle Neoclytus acuminatus acuminatus. J Chem Ecol 30:1493-1507

Lacey ES, Moreira JA, Millar JG, Hanks LM (2008) A male-produced aggregation pheromone blend consisting of alkanediols, terpenoids, and an aromatic alcohol from the cerambycid beetle Megacyllene caryae. J Chem Ecol 34:408-417

Landolt PJ, Brumley JA, Smithhisler CI, Biddick LL, Hofstetter RW (2000) Apple fruit infested with codling moth are more attractive to neonate codling moth larvae and possess increased amounts of $(\mathrm{E}$, E)- $\alpha$-farnesene. J Chem Ecol 26:1685-1699

Lingafelter SW, Hoebeke ER (2002) Revision of Anoplophora (Coleoptera: Cerambycidae). Entomol. Soc. Wash. 236 pp., $41 \mathrm{pl}$

Li D, Tokoro M, Nacashima T (1999) Mechanism of adult action and mating in Anoplophora glabripennis (Motsch.). J Beijing For Univ 21:33-36

Meng PS, Trotter RT, Keena MA, Baker TC, Yan S, Schwartzberg EG, Hoover K (2014) Effects of ppheromone and plant volatile release rates and ratios on trapping Anoplophora glabripennis (Coleoptera: Cerambycidae) in China. Environ Entomol 43:1379-1388

Mitchell RF (2012) Chemical communication in cerambycid beetles and the molecular basis of olfaction. PhD Thesis. University of Illinois. $123 \mathrm{pp}$

Mitchell RF, Graham EE, Wong JCH, Reagel PF, Striman BL, Hughes GP, Paschen MA, Ginzel MD, Millar JG, Hanks LM (2011) Fuscumol and fuscumol acetate are general attractants for many species of cerambycid beetles in the subfamily Lamiinae. Entomol Exp Appl 141:71-77

Morewood WD, Hoover K, Neiner P, McNeil J, Sellmer JC (2004) Host tree resistance against the polyphagous wood-boring beetle Anoplophora glabripennis. Ent Exp Appl 110:79-86

Murray KE, Huelin FE (1964) Occurrence of farnesene in the natural coating of apples. Nature 240:80

Nehme ME, Keena MA, Zhang A, Baker TC, Hoover K (2009) Attraction of Anoplophora glabripennis to male produced pheromone and plant volatiles. Environ Entomol 38:1745-1755

Nehme ME, Keena MA, Zhang A, Baker TC, Xu Z, Hoover K (2010) Evaluating the use of male-produced pheromone components and plant volatiles in two trap designs to monitor Anoplophora glabripennis. Environ Entomol 39:169-176

Nowak DJ, Pasek JE, Sequeira RA, Crane DE, Mastro VC (2001) Potential effect of Anoplophora glabripennis (Coleoptera: Cerambycidae) on urban trees in the United States. J Econ Entomol 94:116-122
Pajares JA, Álvarez G, Ibeas F, Gallego D, Hall DR, Farman DI (2010) Identification and field activity of a male-produced aggregation pheromone in the pine sawyer beetle, Monochamus galloprovincialis. J Chem Ecol 36:570-583

Pajares JA, Álvarez AG, Hall DR, Douglas P, Centeno F, Ibarra N, Schroeder M, Teale SA, Wang Z, Yan S, Millar JG, Hanks LM (2013) 2-(Undecyloxy)-ethanol is a major component of the maleproduced aggregation pheromone of Monochamus sutor. Entomol Exp Appl 149:118-127

Rodriguez-Saona C, Poland TM, Miller JR, Stelinski LL, Grant GG, de Groot P, Buchan L, MacDonald L (2006) Behavioral and electrophysiological responses of the emerald ash borer, Agrilus planipennis, to induced volatiles of Manchurian ash, Fraxinus mandshurica. Chemoecology 16:75-86

Silk PJ, Lemay MA, LeClair G, Sweeney J, MaGee D (2010) Behavioral and electrophysiological responses of Tetropium fuscum (Coleoptera: Cerambycidae) to pheromone and spruce volatiles. Environ Entomol 39:1997-2005

Šobotnik J, Hanus R, Kalinovà B, Piskorski R, Cvačka J, Bourguignon T, Roisin Y (2008) (E, E)- $\alpha$-farnesene, an alarm pheromone of the termite Prorhinotermes canalifrons. J Chem Ecol 34:478-486

Sutherland ORW, Wearing CH, Hutchins RFN (1977) Production of $\alpha$-farnesene, an attractant and oviposition stimulant for codling moth, by developing fruit of ten varieties of apple. J Chem Ecol 3:625-631

Tasin M, Anfora G, Ioriatti C, Carlin S, De Cristofaro A, Schmidt S, Bengtsson M, Versini G, Witzgall P (2005) Antennal and behavioral responses of grapevine moth Lobesia botrana females to volatiles from grapevine. J Chem Ecol 31:77-87

Teale SA, Wickham JD, Zhang F, Su J, Chen Y, Xiao W, Hanks LM, Millar JG (2011) A male-produced aggregation pheromone of Monochamus alternatus (Coleoptera: Cerambycidae), a major vector of pine wood nematode. J Econ Entomol 104:1592-1598

Van den Dool I, Kratz PD (1963) A generalization of the retention index system including linear temperature programmed gas-liquid partition chromatography. J Chromatogr 2:463-471

Wickham JD, Xu Z, Teale SA (2012) Evidence for a female-produced, long range pheromone of Anoplophora glabripennis (Coleoptera: Cerambycidae). Insect Sci 19:355-371

Wie JN, Kang L (2006) Electrophysiological and behavioral responses of a parasitic wasp to plant volatiles induced by two leaf miner species. Chem Senses 31:467-477

Yan F, Bengtsson M, Makranczy G, Löfqvist (2003) Roles of $\alpha$-farnesene in the behaviors of codling moth females. Z Naturforsch 58:113-118

Yarden G, Shani A, Leal WS (1996) (Z, E)- $\alpha$-farnesene: an electroantennogram-active component of Maladera matrida volatiles. Bioorg Med Chem 4:283-287

Yasui H, Yasuda T, Fukaya M, Akino T, Wakamura S, Hirai Y, Kawasaki K, Ono H, Narahara M, Kousa K, Fukada T (2007) Host plant chemicals serve intraspecific communication in the white-spotted longicorn beetle, Anoplophora malasiaca (Thomson) (Coleoptera: Cerambycidae). Appl Entomol Zool 42:255-268

Yasui H, Akino T, Fukaya M, Wakamura S, Ono H (2008) Sesquiterpene hydrocarbons: kairomones with a releaser effect in the sexual communication of the white-spotted longicorn beetle, Anoplophora malasiaca (Thomson) (Coleoptera: Cerambycidae). Chemoecology 18:233-242

Zhang A, Oliver JE, Aldrich JR, Wang BD, Mastro VC (2002) Stimulatory beetle volatiles for the Asian longhorned beetle Anoplophora glabripennis (Motschulsky). Z Naturforsch 57:553558

Zhang A, Oliver JE, Chauhan K, Zhao BG, Xia LQ, Xu ZC (2003) Evidence for contact sex recognition pheromone of the Asian longhorned beetle, Anoplophora glabripennis (Coleoptera: Cerambycidae). Naturwissenschaften 90:410-413 